\title{
ANALISIS PENYEBAB TERJADINYA VIBRASI POMPA SISTEM PENDINGIN SEKUNDER PA-02 AP001
}

\author{
Pranto Busono ${ }^{1}$, Santosa Pujiarta ${ }^{2}$ \\ ${ }^{1}$ PRSG-BATAN Serpong, Indonesia \\ Email: pranto@batan.go.id \\ 2 PRSG-BATAN Serpong, Indonesia \\ Email: santosa_p@batan.go.id
}

Diterima: 16 Maret 2021, diperbaiki : 27 April 2021, disetujui : 30 April 2021

\begin{abstract}
ABSTRAK
ANALISIS PENYEBAB TERJADINYA VIBRASI POMPA SISTEM PENDINGIN SEKUNDER PA02 AP001. Telah dilakukan perawatan rutin terhadap pompa pendingin PA-02 AP001 berupa perawatan bulanan, perawatan 3 bulanan dan perawatan tahunan. Beberapa kegiatan yang dilakukan pada perawatan antara lain: pengukuran suhu, pengukuran vibrasi, pengecekan level oli, uji coba pompa, penggantian oli dan kesejajaran. Meskipun telah dilakukan perawatan rutin, pompa pendingin sekunder PA-02 AP001 mengalami vibrasi yang sangat besar yang terjadi pada hari Sabtu tanggal 9 Januari 2021. Adanya vibrasi pada pompa PA-02 AP001 tersebut maka perlu dilakukan analisa untuk mengetahui penyebabnya dan penanganan selanjutnya. Analisa yang dilakukan berupa pengukuran vibrasi, pengukuran kesejajaran poros dan penggantian karet kopling. Setelah penggantian karet kopling, kemudian dilakukan pengukuran vibrasi dan pengukuran kesejajaran poros. Hasil yang diperoleh ternyata tidak terjadi perubahan yang signifikan pada hasil pengukuran vibrasi dan kesejajaran poros. Dengan hasil tersebut, maka terjadinya anomali getaran pada motor PA-02 AP001 bukan disebabkan oleh faktor unbalance, ketidaksejajaran, dan kerusakan pada bantalan. Setelah dilakukan pengujian tanpa beban dan setelah modifikasi struktur baseplate, bahwa vibrasi yang terjadi masih sesuai dengan yang diijinkan. Sehingga dapat disimpulkan bahwa vibrasi disebabkan oleh mechanical looseness.
\end{abstract}

Kata kunci : vibrasi, kesejajaran, mechanical looseness

\begin{abstract}
ANALYSIS OF THE CAUSES OF THE SECONDARY COOLING PUMP VIBRATION PA-02 AP001. The PA-02 AP001 cooling pump has undergone routine maintenance in the form of monthly maintenance, 3-month maintenance and annual maintenance. Some of the activities carried out on maintenance include: temperature measurement, vibration measurement, checking oil level, pump testing, oil change and alignment. Even though routine maintenance has been carried out, the PA-02 AP001 secondary coolant pump experienced a very large vibration which occurred on Saturday, January 9, 2021. The presence of vibration at the PA-02 AP001 pump, it is necessary to do an analysis to determine the cause and further treatment. The analysis is carried out in the form of vibration measurements, measuring the alignment of the shaft and replacing the coupling rubber. After replacing the coupling rubber, vibration measurements and shaft alignment measurements are then carried out. The results obtained do not show any significant changes in the measurement results of vibration and alignment of the shaft. With these results, the occurrence of vibration anomalies on the PA-02 AP001 motor is not caused by unbalance, misalignment, and damage to the bearings. After doing the test without load and after modification of the baseplate structure, that the vibrations that occur are still in accordance with the allowable. So it can be concluded that the vibration is caused by mechanical looseness.
\end{abstract}

Keywords : vibration, alignment, mechanical looseness 


\section{PENDAHULUAN}

SaAs terdiri atas sistem pendingin primer dan sistem pendingin sekunder. Sistem pendingin primer berfungsi untuk mengambil panas hasil reaksi fisi di teras reaktor. Melalui heat exchanger panas dari sistem pendingin primer dipindahkan ke sistem pendingin sekunder. Sistem pendingin sekunder reaktor RSG-GAS mempunyai fungsi utama untuk memindahkan panas dari sistem pendingin primer ke lingkungan.Sistem pendingin sekunder reaktor RSG-GAS meliputi beberapa komponen utama, antara lain: pompa, heat exchanger, katup, sistem perpipaan dan cooling tower. Terdapat tiga unit pompa sentrifugal yang berada di sistem pendingin sekunder. Pada ketiga pompa tersebut dipasang sistem interlock untuk mengatur mode operasi pompa. Sistem interlock akan mengatur mode operasi, dimana maksimum hanya dua pompa yang dapat dioperasikan pada saat yang bersamaan, sedangkan pompa ketiga dalam posisi stand by. Masing-masing pompa disiapkan untuk memenuhi $50 \%$ dari kapasitas sistem sekunder pada kondisi operasi beban penuh. Sehingga setiap pompa didesain mampu mangalirkan fluida dengan laju alir 1.950 $\mathrm{m} 3 /$ jam. Pompa pendingin sekunder terletak di basement gedung bantu dan dihubungkan dengan pipa isap dan tekan. Filter mekanik diletakkan pada bagian isap pompa yang berfungsi untuk menyaring kotoran sebelum air masuk ke pompa. Tipe pompa yang digunakan adalah jenis aliran radial, dimana impeler digerakkan oleh motor induksi. Setiap pompa dihubungkan dengan kopling gesek otomatis yang berfungsi untuk memungkinkan motor bebas beban pada saat awal pompa dioperasikan. Jenis kopling yang digunakan adalah kopling sentrifugal yang memungkinkan beban pompa diambil secara bertahap bila motor telah mencapai kecepatan operasinya. Pompa dibuat dari besi karbon tuang berbentuk keong dan dilengkapi dengan sambungan-sambungan untuk venting dan drainase.

Spesifikasi pompa, kopling, motor, bantalan dan mechanical seal yang digunakan pada sistem pendingin sekunder sebagai berikut. Pompa pendingin sekunder mempunyai kapasitas $1950 \mathrm{~m}^{3} / \mathrm{jam}$, head $28 \mathrm{~m}$ dan daya 200 kwatt pada putaran motor 1450 rpm. ${ }^{[1]}$ Motor listrik yang digunakan mempunyai spesifikasi daya motor 220 Kwatt, putaran 1475 rpm, 380V, 3 phase, frekuensi $50 \mathrm{~Hz}$, IP23 Y- $\Delta$, Ins. Class F. [2] Kopling yang digunakan type MKWN 3154, dengan spesifikasi $\phi$ as pompa $75 \mathrm{~mm}$, panjang output $140 \mathrm{~mm}, \phi$ as motor 90 $\mathrm{mm}$, panjang output $162 \mathrm{~mm}$; diameter dalam karet kopling $15 \mathrm{~mm}$ dan diameter luarnya $36 \mathrm{~mm}$. Sedangkan bantalan yang digunakan yaitu bantalan pada pompa No. 7319 B.UA ${ }^{[3]}$ sebanyak 2 buah dan NU 416 sebanyak 1 buah; bantalan pada motor No. 6219 C3.2Z sebanyak 2 buah. ${ }^{[4]}$ Pompa menggunakan mechanical seal dengan ukuran $80 \times 100 \times 10 \mathrm{~mm}$. Sebagai komponen utama yang berada di sistem pendingin sekunder maka kinerja pompa harus tetap dijaga. Dengan melakukan perawatan rutin. Pelaksanaan perawatan pompa yang telah dilakukan mengacu pada Program Perawatan Sistem RSG-GAS [5], Program Manajemen Penuaan Reaktor RSG-GAS [6] dan Maintenance and repair manual for secondary cooling system ${ }^{[7]}$.

Tindaklanjut dari ketiga acuaan tersebut berupa perawatan rutin yang dilaksanakan dalam bentuk: perawatan bulanan, perawatan 3 bulanan dan perawatan tahunan. Implementasi dari perawatan bulanan yaitu beberapa kegiatan antara lain: pengukuran suhu, pengukuran vibrasi dan pengecekan level oli. Salah satu implementasi dari 
perawatan 3 bulanan yaitu penggantian oli secara rutin. Sedangkan implementasi pada perawatan tahunan yaitu dilakukannya kesejajaran. Selain itu untuk menjaga kinerja pompa maka akan dilakukan uji coba pompa dalam rangka persiapan sarana operasi reaktor. Pada waktu uji coba pompa, juga dilakukan pemantauan kinerja pompa, antara lain dilakukan pengukuran suhu dan pengamatan vibrasi.

Meskipun telah dilakukan perawatan secara rutin, namun masih ada juga muncul permasalahan. Permasalahan terjadi yaitu pada saat pompa pendingin sekunder PA-02 AP001 beroperasi untuk mendukung operasi reaktor teras ke 102 operasi ke IX, maka pompa mengalami vibrasi yang besar. Kejadian ini berlangsung pada hari Sabtu tanggal 9 Januari 2021. Akibat adanya vibrasi pada pompa PA-02 AP001 tersebut maka perlu dilakukan analisa untuk mengetahui penyebab terjadinya vibrasi pada pompa tersebut. Setelah dilakukan analisa ini maka diharapkan dapat diambil langkahlangkah selanjutnya untuk mengetahui penyebab utama vibrasi dan penanganan selanjutnya.

\section{DASAR TEORI}

Getaran atau vibrasi yang terjadi karena rangsangan gaya luar disebut getaran paksa. Jika frekuensi rangsangan sama dengan salah satu frekuensi natural sistem maka akan didapat keadaan resonansi, dan osilasi besar yang berbahaya mungkin terjadi. Sumbersumber eksitasi harmonik adalah ketidak seimbangan pada mesin-mesin yang berputar, gaya-gaya yang dihasilkan oleh mesin torak, atau gerak mesin itu sendiri.[8] Vibrasi atau getaran yang ditimbulkan oleh peralatan yang berputar antara lain: motor, pompa, fan dan sejenisnya akan memberikan petunjuk tentang kondisi dari peralatan tersebut, apakah berada dalam kondisi yang baik ataukah sebaliknya. Sehingga dengan adanya fenomena ini melalui peralatan yang disebut dengan vibrometer maka akan dapat diketahui detail penyebab terjadinya anomali getaran, tentunya setelah dilakukan analisa gelombang pada data yang telah ditangkap oleh vibrometer. Secara umum penyebab terjadinya anomali getaran pada sebuah peralatan yang berputar adalah sebagai berikut : [9]

Unbalance atau imbalance: Unbalance adalah terjadinya pergeseran titik pusat massa dari titik pusat putarnya sehingga akan menimbulkan getaran yang tinggi. Besarnya amplitudo getaran sebanding dengan besarnya putaran (merupakan kuadrat dari putaranya). [10]

Ketidaksejajaran: Vibrasi yang disebabkan oleh penyambungan poros yang tidak simetris dan besarannya tergantung dari ketidaksimetrisan penyambunganya, semakin tidak simteris penyambungan poros pada sebuah peralatan maka menyebabkan vibrasi akan semakin tinggi. Gejala vibrasi yang diakibatkan oleh ketidaksejajaran hampir sama dengan gejala unbalance akan tetapi dengan menggunakan vibrometer yang memadai akan lebih mudah membedakan antara unbalance dan miskesejajaran yaitu dari analisa sudut fasanya. Terdapat beberapa jenis miskesejajaran seperti miskesejajaran pada sambungan kopling, sabuk, rantai, roda gigi dan lain-lain. [10]

Variasi beban: Beban besar
(overload) pada mesin dapat menyebabkan vibrasi yang tinggi. Untuk melakukan analisa dari fenomena ini maka karakstristik pengoperasian mesin harus difahami, sehingga dalam mengukur getaran dasar (baseline vibration) sangat penting untuk memperhatikan variasi getaran terhadap beban, tekanan dan temperatur. [10]

Clearance: Kelonggaran clearance (over clearance) mempunyai karakter 
penampilan vibrasi yang khusus yaitu ketika dilakukan analisa spectrum akan muncul pada 1 x rpm serta harmonic yang tinggi. [10]

Resonansi: Instalasi suatu mesin biasanya terdiri dari rangka, pipa, duct, dan sebagainya, dimana komponenkomponen tersebut mempunyai frekuensi diri (natural frequency), yang didesain besarnya tidak boleh ada yang sama dengan putaran mesin. Jika salah satu atau beberapa komponen yang ada pada mesin itu mempunyai frekuensi diri yang sama besar dengan putaran mesin, maka vibrasi akan menjadi tinggi atau disebut dengan resonansi. [10]

Mechanical looseness: Disebabkan oleh kerenggangan pada suatu mesin yang terjadi karena adanya kerenggangan baut, kerenggangan bantalan, keretakan di pondasi, kerenggangan antara rotor dengan poros, dan sebagainya. Pada motor listrik dan generator, kerenggangan dapat terjadi pada rotor bar atau gulungan rotor maupun stator. [10]

Kerusakan pada gigi: Masalah pada roda gigi adalah masalah yang sangat komplek, oleh karena itu untuk menganalisa permasalahan roda gigi diperlukan pengetahuan dan pengalaman yang memadai. Namun biasanya kerusakan gigi dapat disebabkan oleh keausan, sentuhan antar gigi tidak smooth, bentuk gigi yang tidak sesuai, pelumasan yang tidak baik dan eksentrisitas. ${ }^{[10]}$

Kerusakan pada bantalan: Ada dua jenis bantalan yang memungkinkan terjadinya kerusakan yaitu anti friction bantalan dan sleeve bantalan. Keduanya mempunyai karakter vibrasi yang berbeda, dan juga kerusakan yang ditimbulkannya berlainan. Yang termasuk anti friction bantalan ialah ball bantalan dan roll bantalan, sedangkan sleeve bantalan adalah journal bantalan.
Masalah pada kelistrikan: Vibrasi karena masalah listrik pada mesin-mesin rotasi hanya terjadi pada generator dan motor listrik. Masalah ini biasanya disebabkan oleh ketidakmerataan gaya medan magnet yang bekerja pada rotor atau stator. Hal ini bisa disebabkan karena hubung singkat pada gulungan, kerusakan pada rotor, sumbu rotor dan stator tidak segaris, stator atau rotor tidak bundar benar dan sebagainya. [10]

Gaya Aerodinamis dan Hidrolik: Vibrasi yang disebabkan oleh gaya aerodinamis pada mesin-mesin rotasi sering terjadi pada fan atau blower. Hal ini umumnya dikarenakan adanya turbulensi fluida (udara/gas) yang berlebihan akibat dari pukulan blade dengan fluida tersebut. Sedangkan vibrasi yang disebabkan oleh gaya hidrolik terjadi pada aliran fluida cair seperti pada peralatan pompa, pipa, katup dan sebagainya. Sama seperti pada vibrasi Aerodinamik, vibrasi jenis ini dapat menjadi serius apabila disertai adanya resonansi pada peralatan yang dilalui fluida atau kesalahan desain. [10]

Oil whirl dan oil whip: Vibrasi ini terjadi pada journal bantalan yaitu pada mesin-mesin dengan sistem pelumasan minyak bertekanan, serta mesin putaran tinggi (di atas putaran kritis pertama). [10]

Gesekan (rubbing): Gesekan antara bagian yang berputar dengan bagian yang tetap disebut rubbing. Gesekan ini bisa terjadi secara terputusputus (intermitent) atau secara terus menerus (continue) selama berputar. [10]

Penambahan (beat): Vibrasi ini terjadi karena adanya gaya-gaya vibrasi yang saling terakumulasi dan saling mengurangi secara berulang, baik dari dua buah atau beberapa mesin yang berdekatan di atas satu rangka pondasi yang sama. Kejadian ini biasanya terjadi jika putaran dari mesin-mesin tersebut tidak sama, seperti halnya terdapat dua buah pompa di atas satu rangka pondasi mempunyai putaran 3.000 rpm dan 2.500 
rpm, berdasarkan fenomena ini maka vibrasi masing-masing pompa akan saling berinteraksi satu sama lain dan akan menyebabkan anomali pada vibrasi. [10]

\section{Spektrum Vibrasi}

Spektrum vibrasi, dengan satuan amplitude $\mathrm{mm} / \mathrm{s}$ (atau inch/s) dan frekuensi cpm (cycle per minute) atau $\mathrm{Hz}$, digunakan untuk mendiagnosis (analisa) sumber penyebab dominan vibrasi dari suatu mesin (misalnya vibrasinya cenderung tinggi). Pengukuran spektrum vibrasi ini biasanya dilakukan jika nilai vibrasi overall sudah relatif tinggi.[11]

\section{METODE}

Metodologi yang dikembangkan untuk menganalisa permasalahan vibrasi pada pompa pendingin sekunder tersebut berupa: pengukuran vibrasi, kesejajaran poros dan penggantian karet kopling.

\section{Pengukuran vibrasi}

Pengukuran vibrasi menggunakan alat ukur Fluke 810. Peralatan ini dilengkapi dengan 3 (tiga) sensor untuk mengukur besarnya vibrasi dalam arah radial, tangensial dan aksial. Pengukuran vibrasi dilakukan untuk mengetahui besarnya amplitudo getaran yang terjadi sebelum maupun setelah dilakukan penggantian karet kopling. Vibrasi yang diukur pada bantalan motor sekunder dalam arah radial, tangensial dan aksial serta vibrasi pada baseplate. Secara garis besar langkah pengukuran vibrasi yaitu :

a. Setup peralatan yang diukur: yaitu identifikasi dan input variabel awal pada peralatan yang akan diukur. Variabel tersebut antara lain: nama peralatan; tipe motor; jenis motor dengan VFD atau tidak; tipe bantalan; nominal daya; frekuensi motor; model pemasangan (vertikal atau horizontal); status operasi motor (solo atau couple).

b. Pengukuran vibrasi: meliputi kegiatan yang dilakukan pada saat pengukuran vibrasi. Kegiatan tersebut antara lain: penentuan lokasi yang akan diukur; pemasangan sensor pada motor; pemilihan orientasi sensor; penentuan orientasi kabel; input putaran motor; dan melakukan pengukuran vibrasi.

c. Diagnose: yaitu kegiatan berupa pengambilan data hasil pengukuran. Pada kegiatan ini diperoleh data vibrasi, review dan rekomendasi terhadap kondisi peralatan tersebut. Data vibrasi berisi spektrum vibrasi yang terjadi, informasi amplitudo puncak vibrasi pada kelipatan frekuensi naturalnya, arah vibrasinya (aksial, radial dan tangensial). Review yang diberikan berupa identfikasi kemungkinan kerusakan yang terjadi, skala tingkat kerusakan peralatan yang diukur, dan interprestasi kondisi peralatan serta rekomendasi selanjutnya.

\section{Kesejajaran}

Kesejajaran yang dilakukan berupa pengukuran kesegarisan poros motor dengan poros kopling. Pengukuran dilakukan dengan menggunakan beam optalign prinsip kerja pada peralatan ini berupa menghitung besar penyimpangan yang terjadi antara sinar yang dipancarkan dan yang dipantulkan. Metodologi pada pengukuran kesegarisan ini secara garis besar dapat dijelaskan sebagai berikut:

Pasang peralatan, dimana alat pemancar sinyal berada pada body motor dan peralatan pemantul sinyal 
pada sambungan kopling pompa. Selanjutnya pengaturan kesejajaran antara pemancar sinyal infrared dengan kaca reflector sehingga sinyal yang dipantulkan dapat diterima kembali oleh peralatan pemancar infrared dengan melihat lampu indikator sinyal pada alat pemancar.

Pengukuran dan pembacaan ketidaksejajaran, dengan cara: pengukuran posisi sinar pada arah putaran $90^{\circ}, 180^{\circ}, 270^{\circ}$ dan $360^{\circ}$. Input jarak antara jarak antar cermin reflektor dengan pemancar/penerima signal infra merah $(\mathrm{mm})$, jarak baut pengikat kedua kaki penyangga depan dan belakang motor penggerak $(\mathrm{mm})$, dan jarak antara pemancar/penerima infra merah dengan kaki penyangga depan motor (mm). Pembacaan besarnya

\section{HASIL DAN PEMBAHASAN}

\section{Data hasil pengukuran}

Dalam rangka analisa penyebab terjadinya vibrasi yang sangat besar pada pompa pendingin sekunder PA-02 AP001 telah dilakukan: pengumpulan data yang berkaitan dengan sistem tersebut; melakukan pengencangan baut dan penggantian karet kopling. Pengumpulan penyimpangan ketinggian (Vertikal) kaki penyangga depan dan kaki belakang motor pada layar display alat ukur. Pembacaan besarnya penyimpangan pergeseran kiri dan kanan (Horisontal) dari kaki penyangga motor.

\section{Penggantian karet kopling}

Penggantian karet kopling dilakukan bertujuan untuk mengganti semua karet kopling dengan karet kopling standar. Salah satu kemungkinan penyebab terjadinya vibrasi yang berlebihan yaitu kondisi karet kopling yang sudah rusak. Dengan mengganti karet kopling tersebut diharapkan terjadi perubahan amplitudo vibrasi.

data yang dimaksud berupa; data temperatur operasi, data kesejajaran, dan data vibrasi. Hasil pengukuran temperatur pompa PA-02 AP001 yang telah dilakukan dari bulan oktober 2020 sampai Januari 2021 dapat dilihat pada tabel 1. Dari hasil pengukuran temperatur terlihat bahwa temperatur bantalan tidak mengalami perubahan yang signifikan sehingga dapat disimpulkan vibrasi tidak disebabkan oleh kerusakan bantalan.

Tabel 1. Data hasil pengukuran suhu pompa PA-02 AP001

\begin{tabular}{ccccccccc}
\hline No. & $\begin{array}{c}\text { Tanggal } \\
\text { Pengukuran }\end{array}$ & $\begin{array}{c}\text { Temperatur ijin } \\
(\mathrm{T} \text { lingkungan+50) } \\
\end{array}$ & \multicolumn{6}{c}{ Temperatur hasil pengukuran $\left({ }^{\circ} \mathrm{C}\right)$} \\
\cline { 4 - 8 } & & 1 & 2 & 3 & 4 & 5 & 6 \\
\hline 1 & $18-10-2020$ & 78,4 & 37,8 & 45,5 & 35,1 & 46,4 & 43,0 & 25,9 \\
\hline 2 & $21-10-2020$ & 78,2 & 37,2 & 47,1 & 35,3 & 46,5 & 42,4 & 25,0 \\
\hline 3 & $04-11-2020$ & 77,9 & 37,7 & 40,8 & 34,8 & 45,5 & 43,8 & 24,9 \\
\hline 4 & $02-12-2020$ & 78,1 & 37,3 & 43,2 & 35,0 & 43,1 & 38,2 & 25,2 \\
\hline 5 & $18-01-2021$ & 77,8 & 37,5 & 42,2 & 35,3 & 44,6 & 41,8 & 25,3 \\
\hline \multicolumn{7}{c}{ Keterangan: Posisi pengukuran temperatur bantalan seperti pada gambar 1}
\end{tabular}




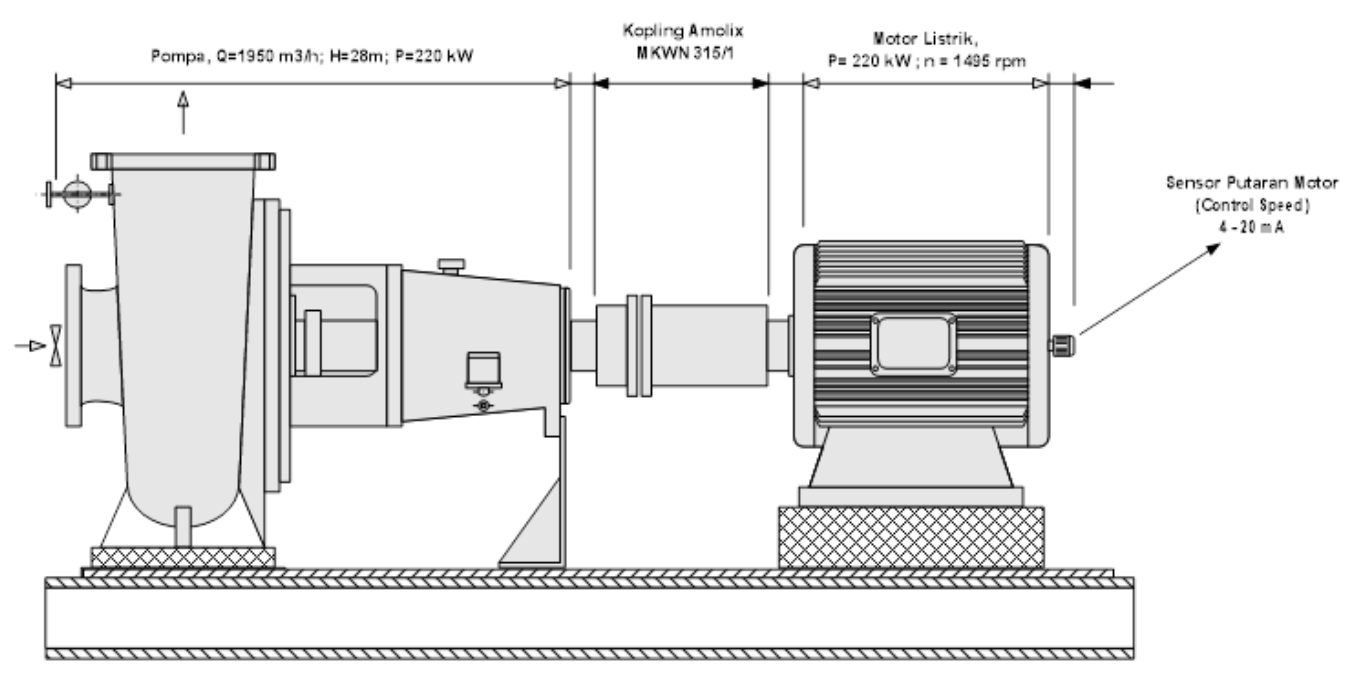

Gambar 1. Unit Pompa pendingin sekunder

Hasil pengukuran vibrasi pada motor yang dilakukan sebelum dan sesudah baut pengikat motor dikencangkan dan dilakukan penggantian karet kopling dapat dilihat pada tabel 2 .

Tabel 2. Hasil pengukuran vibrasi sebelum dan sesudah pengencangan baut pengikat dan penggantian karet kopling

\begin{tabular}{|c|c|c|c|c|}
\hline \multirow[b]{2}{*}{ No } & \multirow[b]{2}{*}{ Lokasi } & \multirow[b]{2}{*}{ Axis } & \multicolumn{2}{|c|}{ Vibrasi (mm/sec) } \\
\hline & & & $\begin{array}{l}\text { Sebelum penggantian } \\
\text { karet kopling }\end{array}$ & $\begin{array}{c}\text { Sesudah } \\
\text { penggantian } \\
\text { karet kopling }\end{array}$ \\
\hline 1 & Bantalan motor luar & Aksial & 5,08 & 3,30 \\
\hline 2 & Bantalan motor dalam & Aksial & 6,60 & 8,38 \\
\hline 3 & Bantalan motor dalam & Radial & 7,87 & 4,57 \\
\hline 4 & Bantalan motor luar & Radial & 10,67 & 10,16 \\
\hline 5 & Bantalan motor dalam & Tangensial & 50,55 & 50,80 \\
\hline 6 & Bantalan motor luar & Tangensial & 76,71 & 72,64 \\
\hline
\end{tabular}

Sebagai pembanding hasil pengukuran tersebut, berikut ditampilkan hasil pengukuran oleh pihak ketiga. Hasil pengukuran tersebut dapat dilihat pada 3 berikut.

Tabel 3. Hasil pengukuran vibrasi oleh pihak ketiga

\begin{tabular}{|c|c|c|c|c|}
\hline \multirow{2}{*}{ No } & \multirow{2}{*}{ Komponen } & \multicolumn{3}{|c|}{ Vibrasi (mm/sec) } \\
\hline & & Radial & Aksial & Tangensial \\
\hline 1 & Bantalan motor luar & 12,6 & 11,0 & 58,0 \\
\hline 2 & Bantalan motor dalam & 29,0 & 15,9 & 39,5 \\
\hline 3 & Bantalan pompa luar & 1,3 & 2,1 & 2,3 \\
\hline 4 & Bantalan pompa dalam & 1,6 & 2,3 & 4,5 \\
\hline 5 & Baseplate & & & 3,8 \\
\hline
\end{tabular}


Gambar 2. sampai gambar 4. berikut menunjukkan spektrum vibrasi motor pada frekuensi natural sebelum dan

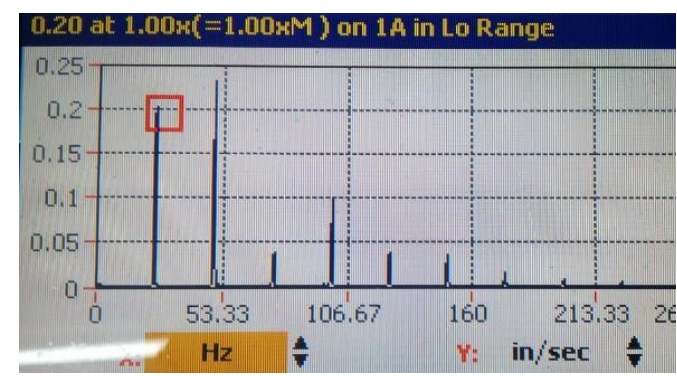

a. sebelum baut dikencangkan

Gambar 2. Spektrum vibrasi arah aksial pada frekuensi natural

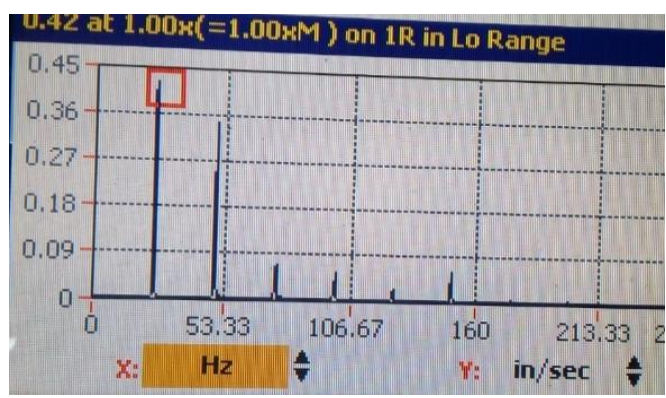

a. sebelum baut dikencangkan sesudah dilakukan pengencangan baut pengikat.

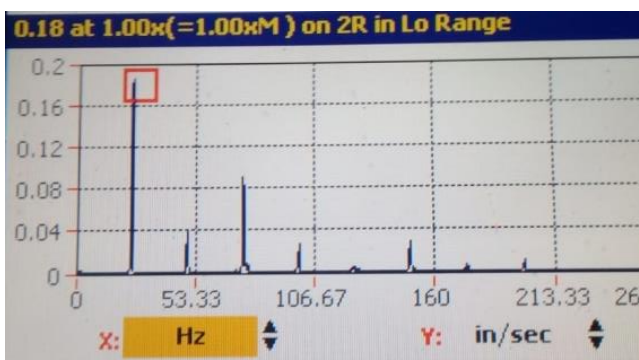

b. setelah baut dikencangkan

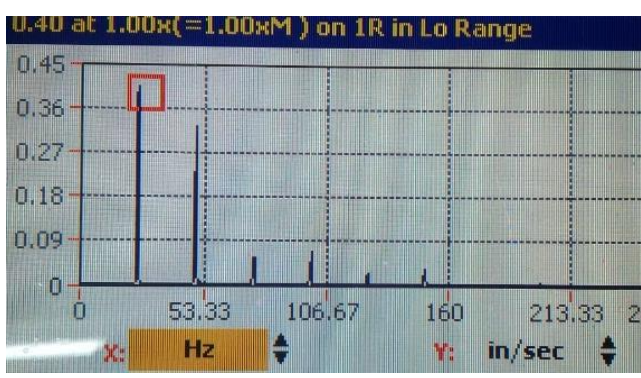

b. setelah baut dikencangkan

Gambar 3. Spektrum vibrasi arah radial pada frekuensi natural

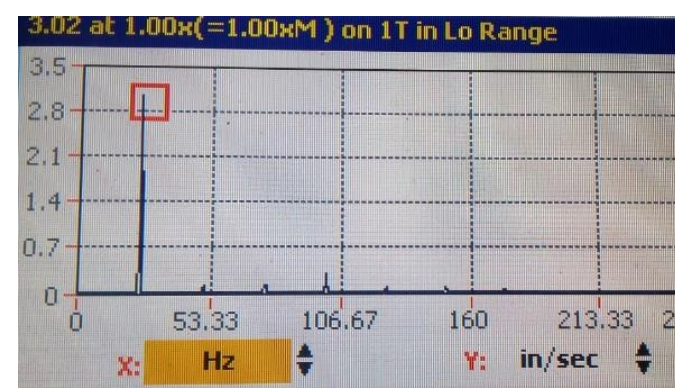

a. sebelum baut dikencangkan

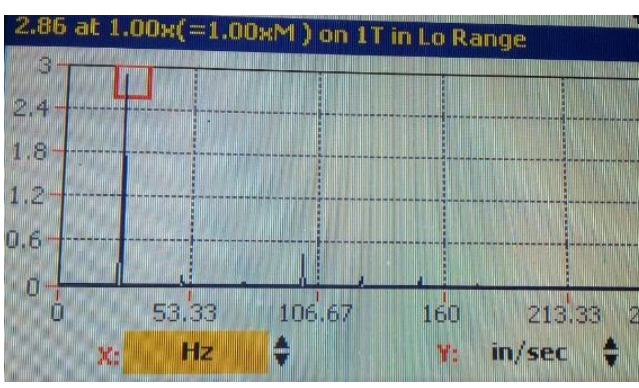

b. setelah baut dikencangkan

Gambar 4. Spektrum vibrasi arah tangensial pada frekuensi natural

Pada tabel 4. berikut ditunjukkan hasil pengukuran kesegarisan antara poros motor dengan poros kopling yang dilakukan sebelum dan sesudah penggantian karet kopling dan baut pengikat kaki-kaki motor dikencangkan. 
Tabel 4. Hasil pengukuran kesejajaran antara poros motor dengan poros kopling

\begin{tabular}{|c|c|c|c|c|c|c|c|c|}
\hline \multirow{3}{*}{$\begin{array}{l}\text { Pengukuran } \\
\text { ke }\end{array}$} & \multicolumn{8}{|c|}{ Besarnya penyimpangan $(0,1 \mathrm{~mm})$} \\
\hline & \multicolumn{2}{|c|}{$\begin{array}{l}\text { Ketinggian kaki } \\
\text { depan }\end{array}$} & \multicolumn{2}{|c|}{$\begin{array}{l}\text { Ketinggian kaki } \\
\text { belakang }\end{array}$} & \multicolumn{2}{|c|}{$\begin{array}{c}\text { Arah horizontal } \\
\text { kaki depan }\end{array}$} & \multicolumn{2}{|c|}{$\begin{array}{l}\text { Arah horizontal } \\
\text { kaki belakang }\end{array}$} \\
\hline & Sebelum & Sesudah & Sebelum & Sesudah & Sebelum & Sesudah & Sebelum & Sesudah \\
\hline 1 & -11 & -14 & -8 & -10 & 2 & 4 & 14 & 19 \\
\hline 2 & -13 & -12 & -11 & -6 & 2 & 5 & 11 & 19 \\
\hline 3 & -15 & -12 & -14 & -6 & 3 & 6 & 16 & 22 \\
\hline 4 & -12 & -16 & -9 & -12 & 3 & 6 & 14 & 20 \\
\hline 5 & -9 & -14 & -3 & -9 & 2 & 7 & 15 & 22 \\
\hline 6 & -12 & -14 & -9 & -9 & 3 & 1 & 14 & 14 \\
\hline Rata-rata & -12 & $-13,7$ & -9 & $-8,7$ & 2,5 & 4,8 & 14 & 19,3 \\
\hline
\end{tabular}

\section{Pembahasan}

Semua peralatan yang berputar pasti mengalami vibrasi dalam kondisi normal, hal ini juga terjadi pada motor pompa PA02 AP001 yang mengalami vibrasi yang cukup besar. Faktor-faktor seperti: variasi beban, clearance, resonansi, masalah roda gigi, masalah kelistrikan, unbalance, ketidaksejajaran, kerusakan bantalan dan mechanical looseness akan dapat menimbulkan vibrasi yang berlebihan. Vibrasi yang berlebihan pada motor pompa PA-02 AP001 bukan disebabkan oleh faktor variasi beban, clearance, resonansi dan masalah roda gigi. Sedangkan faktor yang mungkin menjadi penyebab terjadinya vibrasi pada motor pompa tersebut adalah unbalance, ketidaksejajaran, Mechanical looseness dan kerusakan pada bantalan. Berikut akan dilakukan analisa faktor kemungkinan penyebab terjadinya vibrasi tersebut berdasarkan data pengujian yang telah dilakukan.

- Unbalance atau imbalance: Unbalance adalah terjadinya pergeseran titik pusat massa dari titik pusat putarnya sehingga akan menimbulkan getaran yang tinggi. Besarnya amplitudo getaran sebanding dengan besarnya putaran (merupakan kuadrat dari putarannya). Motor pompa sekunder Dari data pengukuran vibrasi tabel 2 , terlihat bahwa vibrasi yang terjadi pada pada pompa sangat kecil (Vibrasi $\leq 25,4 \mathrm{~mm} / \mathrm{sec}$ ). Dengan hasil ini maka bisa dikatakan bahwa vibrasi bukan disebabkan adanya unbalance.

Ketidaksejajaran: Vibrasi yang disebabkan oleh penyambungan poros yang tidak simetris dan besarannya tergantung dari ketidaksimetrisan penyambunganya, semakin tidak simeteris penyambungan poros pada sebuah peralatan maka menyebabkan vibrasi akan semakin tinggi. Pada rangkaian motor-kopling-pompa, vibrasi yang terjadi pada kondisi ini sebagian besar disebabkan oleh kondisi unbalance. Kondisi unbalance bisa disebabkan oleh kesejajaran yang kurang bagus, karet kopling yang telah rusak atau baut pengikat motor kurang kencang. Untuk melihat kemungkinan ini telah dilakukan pengukuran kesejajaran dan penggantian karet kopling. Dari hasil pengukuran vibrasi yang dilakukan sebelum dan setelah penggantian karet kopling dan pengencangan baut pengikat motor, terlihat bahwa perbedaan hasilnya tidak terlalu signifikan sehingga kondisi karet kopling maupun kekencangan baut bukan menyebabkan vibrasi yang terjadi pada motor pompa (tabel 2 dan tabel 3). Kondisi ini juga didukung oleh 
hasil kesejajaran yang telah dilakukan sebelum dan setelah pengencangan baut dan penggantian karet kopling. Hasil yang diperoleh ternyata masih dibawah nilai yang diijinkan $(\leq 5 \mathrm{~mm})$ sehingga dapat disimpulkan bahwa vibrasi yang terjadi pada motor pompa bukan disebabkan kesejajaran (tabel 4).

Kerusakan pada bantalan: Ada dua jenis bantalan yang memungkinkan terjadinya kerusakan yaitu anti friction bantalan dan sleeve bantalan. Keduanya mempunyai karakter vibrasi yang berbeda, dan juga kerusakan yang ditimbulkan berlainan. Yang termasuk anti friction bantalan ialah ball bantalan dan roll bantalan, sedangkan sleeve bantalan adalah journal bantalan. Vibrasi pada kondisi ini, hanya ditentukan oleh kondisi bantalan dari motor itu. Sedangkan berdasarkan data perawatan, diperoleh data bahwa motor dan bantalannya termasuk baru, dimana penggantian motor dan bantalan dilakukan pada Desember $2019 \quad$ sehingga kemungkinan terjadinya kerusakan bantalan sangat kecil. Selain itu beberapa hal berikut sangat mendukung kondisi tersebut, antara lain:

a. Temperatur kerja bantalan masih sangat jauh dibawah temperatur ijin, hal ini terlihat pada hasil pengukuran yang telah dilakukan, seperti pada tabel 1.

b. Besar amplitudo pada bantalan motor dalam arah Aksial dan arah radial yang kecil (Amplitudo $\leq 25.4$ $\mathrm{mm} / \mathrm{sec}$ ) yang berarti bantalan masih dalam kondisi bagus. Sedangkan amplitudo dalam arah tangensial sangat besar $\geq 25,4 \mathrm{~mm} / \mathrm{sec}$ menunjukkan bahwa vibrasi disebabkan oleh faktor lainnya hasil pengukuran dapat dilihat pada tabel 2 dan tabel 3.

Berdasarkan data hasil pengukuran temperatur bantalan bahwa temperatur masih lebih kecil dari temperatur ijin; dan besarnya vibrasi dalam arah aksial dan radial masih dibawah vibrasi ijin, maka kemungkinan sangat kecil bahwa vibrasi disebabkan oleh kerusakan bantalan.

Mechanical looseness: Disebabkan oleh kerenggangan pada suatu mesin yang terjadi karena kerenggangan baut, kerenggangan bantalan, keretakan di pondasi, kerenggangan antara rotor dengan poros, dan sebagainya. Pada motor listrik dan generator, kerenggangan dapat terjadi pada rotor baru atau gulungan rotor maupun stator. Kemungkinan vibrasi yang disebabkan oleh konstruksi baseplate motor dan pompa. Beberapa hal yang mendukung kondisi tersebut yaitu:

- Hasil pengukuran vibrasi pada motor yang dilakukan sebelum dan sesudah dilakukan pengencangan baut menunjukkan bahwa vibrasi dalam arah tangensial sangat besar dibandingkan arah radial maupun aksial (Tabel 2).

- Berdasarkan hasil pengukuran vibrasi pada baseplate yang telah dilakukan oleh pihak ketiga (KSB) pada tanggal 01-022021 memperoleh hasil yang sangat besar $(3,8 \mathrm{~mm} / \mathrm{s})$, tabel 4. 
- Hasil pengujian vibrasi motor dalam kondisi tanpa beban (solo run), memastikan bahwa vibrasi bukan disebabkan oleh motor.

- Selain setelah dilakukan modifikasi pada rangka baseplate, diperoleh bahwa vibrasi yang terjadi masih dibawah yang diijinkan ( $\leq$ $25,4 \mathrm{~mm} / \mathrm{sec}$ ).

\section{KESIMPULAN}

Berdasarkan data hasil pengukuran dan analisa yang telah dilakukan terhadap kondisi vibrasi yang terjadi pada pompa pendingin sekunder PA-02 AP001 dapat disimpulkan sebagi berikut:

1. Terjadi vibrasi pada pompa tersebut kemungkinan besar bukan disebabkan oleh kondisi bantalan baik pada motor maupun pada pompa.

2. Kondisi karet kopling maupun kesejajaran poros antara motorkopling-pompa masih baik sehingga vibrasi bukan disebabkan oleh faktor ini.

3. Kemungkinan terbesar vibrasi yang terjadi disebabkan oleh kondisi baseplate dalam hal ini disebabkan oleh rangka dudukan motor dan pompa. Hal ini didukung oleh beberapa hal, antara lain hasil pengukuran vibrasi yang terbesar terjadi dalam arah tangensial serta hasil pengukuran vibrasi pada baseplate yang hasilnya sangat besar.

Direkomendasikan untuk dilakukan penggantian struktur baseplate yang lebih rigid untuk mengatasi vibrasi pada motor pompa pendingin sekunder PA-02 AP001.

\section{DAFTAR PUSTAKA}

[1] Standardized chemical pumps to EN 22858/ISO 2858/ISO 5199.

[2] Schorch; Electrical machines, Drive systems and system engineering, Frame size 63-450 /I 2 G EExd(e) IIC(B) T4, M1.23e- 2001.

[3] www.skf.com on 2021-02-02, Technical specification ball bearing 7319 B UA.

[4] www.skf.com on 2021-02-02, Technical specification ball bearing $62192 Z$.

[5] Program Perawatan Sistem RSGGAS, No. Ident : 001.001/RN 00 02/RSG 3, tgl 5 Agustus 2019

[6] Program Manajemen Penuaan Reaktor RSG-GAS, No. Ident: 002.001/RN 00 02/RSG 3, tgl 1 Juni 2014.

[7] Maintenance and repair manual for secondary cooling system, MRM Part 1 Chapter 2.01 page 4-17

[8] William T. Thomson, Dra. Lea Prasetio, M.Sc.: Teori Getaran dengan Penerapan, Edisi kedua, Jakarta, 1995.

[9] How To Implement An Effective Condition Monitoring Program Using Vibration Analysis, James E. Berry.

[10] https://anugerahjayabantalan.com/p enyebab-terjadinya-vibrasi-simakpenjelasan-nya.html

[11]RN Harjono, Tedjo Sukmadi, Karnoto: Pemanfaatan spektrum vibrasi untuk mengindikasikan kerusakan motor induksi di PLTU Indramayu $3 \times 330 \mathrm{MW}$, ejournal3.undip.ac.id 